This item was submitted to Loughborough's Research Repository by the author.

Items in Figshare are protected by copyright, with all rights reserved, unless otherwise indicated.

\title{
Practical limit of synthetic inertia in full converter wind turbine generators: simulation approach
}

PLEASE CITE THE PUBLISHED VERSION

http://dx.doi.org/10.1109/SIELA.2016.7543007

PUBLISHER

(C) IEEE

VERSION

AM (Accepted Manuscript)

\section{PUBLISHER STATEMENT}

This work is made available according to the conditions of the Creative Commons Attribution-NonCommercialNoDerivatives 4.0 International (CC BY-NC-ND 4.0) licence. Full details of this licence are available at: https://creativecommons.org/licenses/by-nc-nd/4.0/

\section{LICENCE}

CC BY-NC-ND 4.0

\section{REPOSITORY RECORD}

Gonzalez-Longatt, Francisco M., Andrea Bonfiglio, Renato Procopio, and Dimitar Bogdanov. 2019. "Practical Limit of Synthetic Inertia in Full Converter Wind Turbine Generators: Simulation Approach". figshare. https://hdl.handle.net/2134/23016. 


\section{Practical Limit of Synthetic Inertia in Full Converter Wind Turbine Generators: Simulation Approach}

\section{F. Gonzalez-Longatt}

The Wolfson School: Electronic,

Electrical, and Systems Engineering

Loughborough University

Loughborough, UK

fglongatt@fglongatt.org

\author{
A. Bonfiglio, R. Procopio
}

Department of Electrical, Electronic,

Telecommunications Eng. and Naval Arch. University of Genoa

genoaa.bonfiglio@unige.it

renato.procopio@unige.it

\author{
D. Bogdanov \\ Technical University of Sofia, \\ Faculty of electrical engineering, \\ 18, Kl. Ohridski Blvd. \\ 1000 Sofia, Bulgaria \\ dbogdanov@tu-sofia.bg
}

\begin{abstract}
The massive integration of wind power using power converters has imposed several challenges to the future power system. One of them is related to the decoupling effect of new power sources from the $\mathrm{AC}$ power grid, incapacitating their natural frequency response. This situation negatively affects the system frequency response. This aim of this paper is to establish the practical limits of synthetic inertia gain in the inertia controller used in full converter wind turbine generators. Timedomain simulations using a simple test system are used for illustrative purposes in this paper. This paper considers full converter wind turbine (FCWT) -Type 4 using direct-drive (DD) permanent magnet synchronous generator (PMSG). The main contribution of this paper is to demonstrate there is a limit of the inertia controller gain $\left(H_{s y n}\right)$ and its relationship with the real wind turbine inertia constant $\left(\boldsymbol{H}_{W T G}\right)$.
\end{abstract}

Keywords - control systems; frequency response; frequency stability; wind power; wind turbine.

\section{INTRODUCTION}

System frequency $(f)$ is a constantly varying variable that is measured and controlled by the second-by-second (real time) balance between total power system demand $\left(P_{L}\right)$ and total generation $\left(P_{G}\right)$ [1], [2]. Any power imbalance between generation and demand produces a change in the system frequency. If power demand is greater than power generation $\left(P_{L}>P_{G}\right)$, the system frequency falls $(f \downarrow)$ while if the power generation is greater than demand $\left(P_{G}>P_{L}\right)$, the frequency rises $(f \uparrow)$.

The frequency control has been traditionally performed by the control of all the conventional synchronous generators in power system [3]. Traditionally, wind farms (WFs) have not taken part in the system frequency support, because they do not provide ancillary services for grid support; as a consequence, this burden is shared by the traditional power plants (TPP) based on synchronous generators (SG) [4].

However, global penetration of wind power into the power system increases, the installed capacity of the wind and solar power in the EU-28 countries reached a capacity of respectively $142 \mathrm{GW}$ and $39 \mathrm{GW}$ which corresponds to $15.6 \%$ and $11.2 \%$ of the total European electricity generation capacity (2015) [5].
After a significant growth in the penetration of renewables in the power systems, the grid code requirements are gradually becoming more demanding [3]. Apart from the well-known fault-ride through capability for wind farms, the frequency stability support is also becoming an important aspect in grid codes around the world. Massive integration of wind power is expected to be part of the power system and therefore some countries have started to establish new grid codes relevant to wind farms. The inclusion of frequency response in grid code has being discussed by several transmission system operators. In fact, the WFs that are able to restore generation/demand balance are required in some European countries already but mainly for over-frequency conditions.

The responsibility of frequency control is managed in continental Europe by European Network of Transmission System Operators for Electricity (ENTSO-E) and the normal operational practice is to keep frequency deviations less than $\pm 1 \%$ of the nominal value $(50 \mathrm{~Hz})$. National Grid plc is responsible for the frequency control in GB [6], and its grid code defines the mandatory frequency response as a needed service to maintain the frequency within statutory $(49.5 \mathrm{~Hz}$ $50.5 \mathrm{~Hz})$ and operational limits $(49.8 \mathrm{~Hz}-50.2 \mathrm{~Hz})$. National Grid achieves this by using one of three response services: primary, secondary and high-frequency response.

During a system frequency disturbance (SFD) the generation/demand power balance is lost, the system frequency will change at a rate initially determined by the total system inertia $\left(H_{T}\right)$. However, future power systems will increase the installed power capacity (MVA) but the effective system inertial response will stay the same nowadays [7]. The result is deeper frequency excursions of system disturbances.

Many modern wind turbines (WT) are equipped with control devices providing the ability to control active power output in response to grid frequency in ways that are important to overall grid performance and security. The high/low power converters typically tend to decouple energy sources from the pre-existent AC power systems [8], [9].

There are several good papers [1]-[3], [10], and technical reports [1]-[11] dealing with theory [12]-[13], modelling [14] and simulation [15] of inertial response of wind turbine generators (WTG) and some of them provide general ideas about possible impacts on power systems and their effects on 
transient under-frequency response [16]-[17]. Even some controls strategies have been proposed to mitigate the impact of reduced inertia [18].

This aim of this paper is to establish the practical limit of synthetic inertia gain in the inertia controller used in full converter wind turbine generators. Time-domain simulations using a simple test system are used for illustrative purposes in this paper. This paper considers full converter wind turbine (FCWT) -Type 4 using direct-drive (DD) permanent magnet synchronous generator (PMSG). Time domain simulation are used to establish the practical limit of synthetic inertia gain in the inertia controller used in full converter wind turbine generators.

Section II presents the concept of synthetic inertia and the controller used to enable this frequency support. This controller together with the full WT model is using for simulation purposes. Section III uses time domain simulations to establish the practical limit of synthetic inertia gain in the inertia controller used in full converter wind turbine generators. Section IV presents the main conclusion of this paper. The main contribution of this paper is to highlight there is a physical limit between the synthetic inertia $\left(H_{s y n}\right)$ gain used for the inertia controller and the real wind turbine inertia constant $\left(H_{W T G}\right)$. This limit is extremely important in order to avoid overloading the power converter, but, at the same time, to avoid the wind turbine stall.

\section{SYNTHETIC INERTIA CONTROLLER}

Many modern wind turbines (WT) have the ability to control active power output in response to grid frequency in ways that are important to overall grid performance and security. Synthetic inertia concept allows a controller to the take the kinetic energy from a WT rotating mass. This controller is well-explained in several publications [15], [12].

The WT industry has created several controllers for modern WTGs in order to provide an inertial response (and governor response in some cases) for large frequency deviations and for a short-duration: Artificial, Emulated, Simulated, or Synthetic Inertial. Examples of synthetic inertia controlled commercially available for WTG are General Electric WindINERTIA ${ }^{\text {TM }}$ [19], ENERCON $^{\circledR}$ Inertia Emulation [20]. The objective of the synthetic inertia control is "to extract the stored inertial energy from the moving part on WTGs" [21]. There are several versions of synthetic inertia controllers; however they can be classified into two main approaches [9], [2]: (a) Releasing "hidden" inertia and (b) Reserve capacity in pitch.

This paper uses the concept of Releasing "hidden" inertia to implement the inertia response of WTGs. This control loop increases the electric power output of the WTG during the initial stages of a significant downward frequency event (see Fig. 1) [3]. The inertial power (extra-active power, $\Delta P$ in p.u.) required by the controller is achieved by:

$$
\Delta P=2 H_{s y n} \times f_{s y s} \times \frac{d f_{s y s}}{d t}
$$

where $H_{\text {syn }}$ express the synthetic inertia (sec) and $f_{\text {sys }}$ system frequency $(\mathrm{pu})$. Implementation of synthetic inertia controller is depicted in Fig. 1.

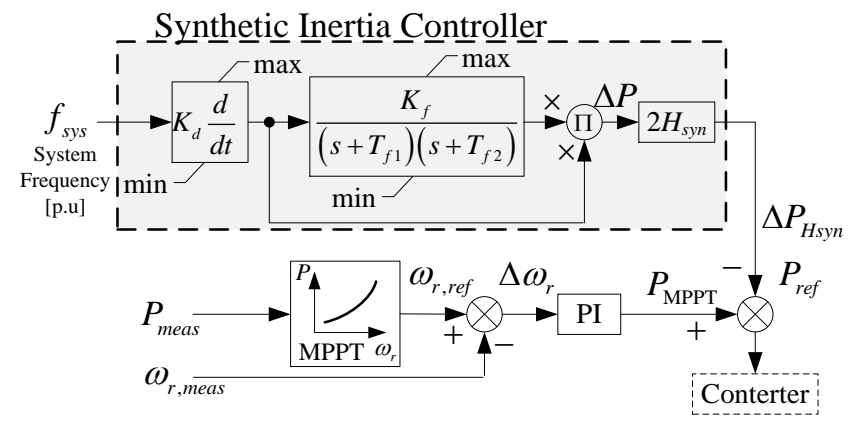

Fig. 1. Representative diagram of Maximum Power Point Tracking (MPPT) controller and Synthetic Inertia Controller (shadowed) [3].

\section{Simulation AND RESUltS}

This section presents the main aspects of the system modelling used for simulation purposes in this paper. The test system is an extremely simple two voltage level transmission system, as shown in Figure 3. The test system looks simple a simple glance but it is enough to allow a good understanding on the SFR.

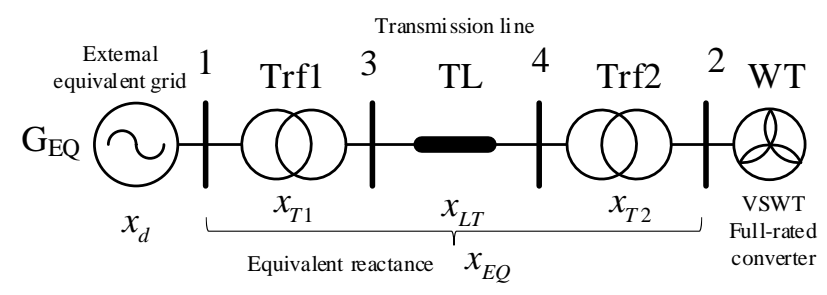

Fig. 2. Test system: Representative transmission system including an equivalent WTG

The Test System comprises of a relatively large generator representing a simplified model of an equivalent external grid $\left(\mathrm{G}_{\mathrm{EQ}}\right)$ connected to a full-rated converter connecting a variable speed wind turbine (VSWT, see Fig 3). The transmission is assumed to be ideal without active power losses $\left(\underline{r}_{E Q}=0\right)$ and reactances of transformers (Trf1 and Trf2) and transmission line (TL) can be combined together (bus 3 and 4 disappear) and an equivalent reactance $\left(x_{E Q}=x_{T 1}+x_{L T}+x_{T 2}\right)$ is used instead. Details the modelling of the different aspects relevant for SFR are presented in the next subsections. The main large generator representing a simplified model of an equivalent external grid is assumed to have a total inertia $\left(H_{n e t}\right)$ equal to $40 \mathrm{~s}$ (on machine power base).

\section{A. Wind Turbine (WT) Model}

Fig. 3 illustrates the general structure of a variable-speed wind turbine (VSWT) with a direct-drive (DD) permanent magnet synchronous generator (PMSG). This wind turbine uses a full-rated power converter in the form of back-to-back topology. The models used a full-rated converter and their details are taken from [9, 22, 23]. Models parameters used are escalated to simulate an equivalent $5 \mathrm{MW}$ wind turbine. 


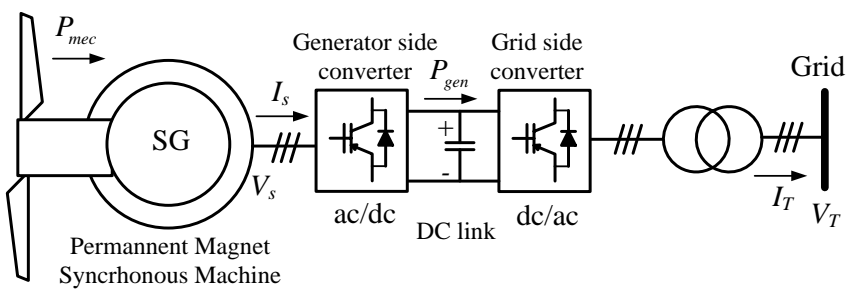

Fig. 3. The general structure of a variable-speed wind turbine (VSWT) with a direct-drive synchronous generator with a full-rated power converter as an interface to grid.

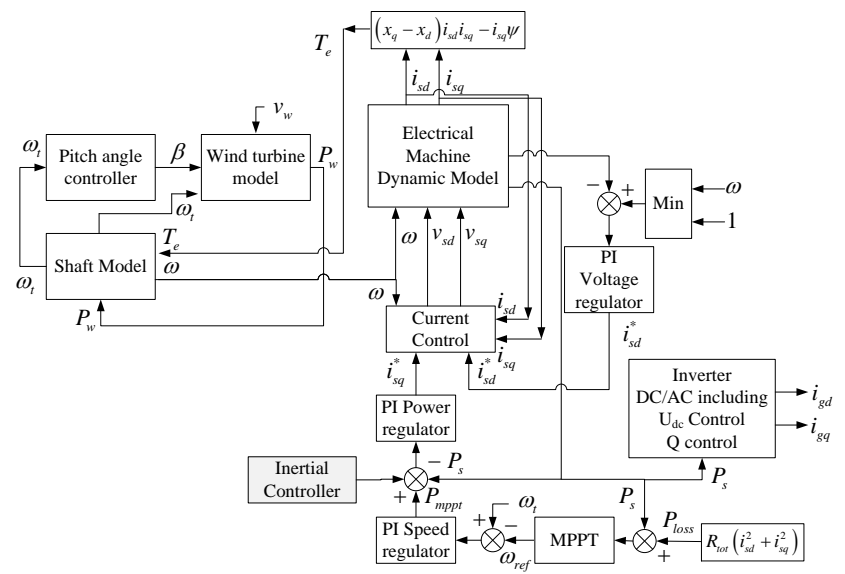

Fig. 4. A representative block diagram of main elements, controller, and signals using the model of VSWT with a DD synchronous generator with a FRPC.

Fig. 4 depicts a representative block diagram of the main components and controller considering on the modelling of VSWT with a DD synchronous generator with a FRPC as an interface to the grid. The VSWT rotor model consists of the classical polynomic relationship between wind speed and mechanical power. A simple a classical two mass representation is used to model the mechanical shaft. MPPT controller is included in order to provide the speed control of the wind turbine and it is aimed to maximize its power production. Pitch angle controller is counted in the model targeting to decrease of the power extracted from the wind at very high wind speed regimes. The generator side converter includes two main control loops: the active power/speed control loop and the voltage control loop. Those control loops are used to provide the reference signals for the two inner current control loops. The grid side converter includes two outer control loops, regulating the voltage $\left(U_{d c}\right)$ on the DC link and the reactive power $\left(Q_{n e t}\right)$ delivered to the network. Again, those outer loops will provide the reference signals for the two inner current control loops. More specific details about the modelling of the WTG are beyond the scope of this paper, however, further details can be found on [24], [25].

\section{Simulation AND Results}

This section presents results of time domain simulations used in order to establish the practical limit of synthetic inertia gain in the inertia controller. The Test System comprises of a relatively large generator representing a simplified model of an equivalent external grid $\left(G_{E Q}\right)$ connected to a full-rated converter connecting a VSWT (see Fig 2). System model and wind turbine controllers (as described in section II and III) are implemented using Matlab/Simulink. The system frequency disturbance consists of a simulated generator outage, it is simulated in the Test System as a sudden increase on active power demand $\left(\Delta P_{L}\right)$. The disturbance is introduced at the time, $\underline{t_{0}}=10.0 \mathrm{~s}$.

Initially, the gain of the synthetic inertia controller $\left(H_{s y n}\right)$ is assumed equal to a quarter of the total physical inertia of the WTG $\left(H_{W T G}\right)$, the system performance is evaluated in three different conditions of power imbalance $\left(\Delta P_{L}=0.30,0.60\right.$ and $0.90 \mathrm{pu}$ considering the WTG power as a base, see Fig. 5).

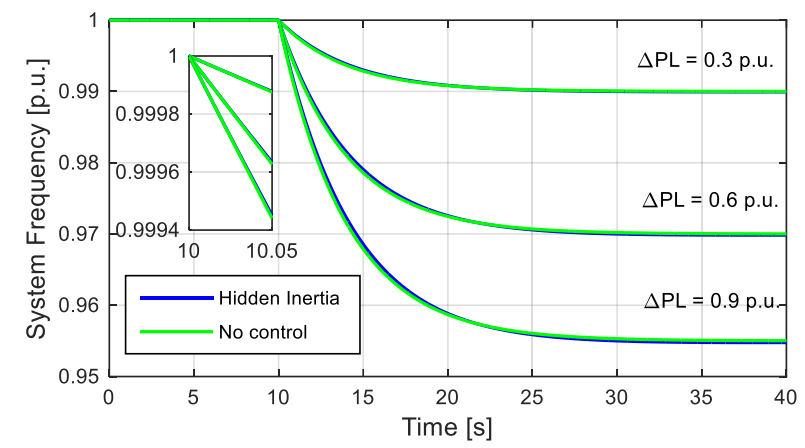

Fig. 5. Simulation results of system frequency dynamic response during system frequency disturbance considering three different power imbalances $\left(\Delta P_{L}\right), H_{s y n}=0.25 H_{W T G}$.
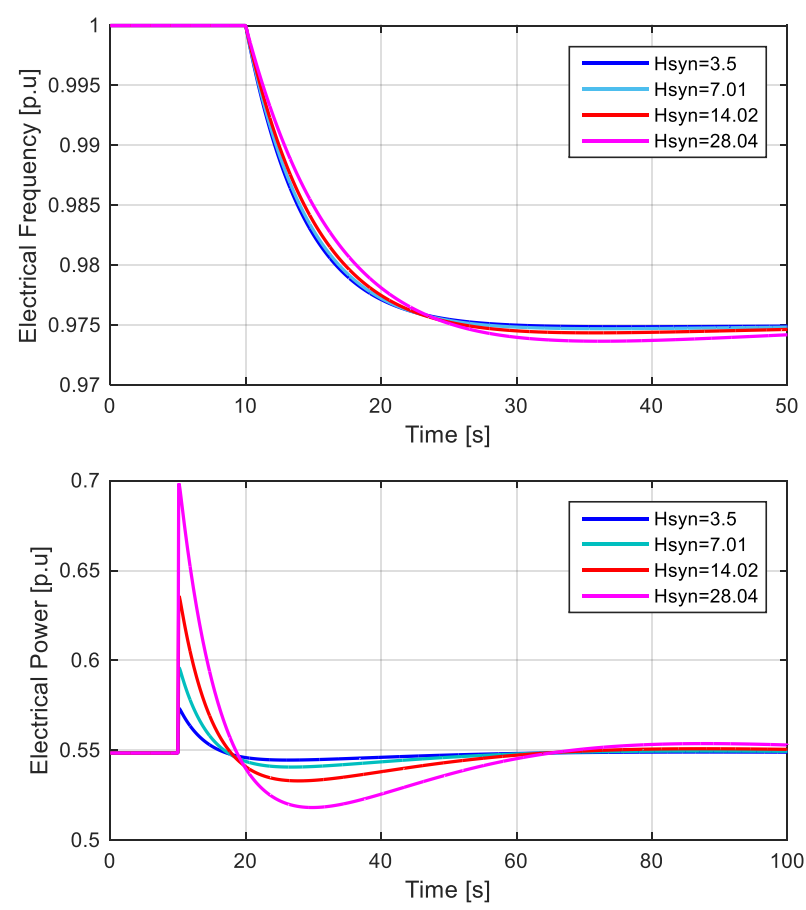

Fig. 6. Simulation results of system frequency response considering several values of synthetic inertia controller, $H_{s y n}$.

Fig 5 show the system frequency response during a sudden load increase, the disturbance size is increased $\left(\Delta P_{L}\right)$ and the initial transient of the frequency is supported by inertial power contribution provided by the inertia controller, the inertial 
power becomes less and less impacting while the frequency transient tent to extinguish. The inertial power contribution and the frequency support contribution are higher for bigger power imbalance, associated with a wider decreasing rate of frequency.

Now, the gain of the synthetic inertia controller $\left(H_{s y n}\right)$ is changed considering several values, the system frequency response and the inertial power or active power are presented on Fig 6. The effect of increasing synthetic inertia controller $\left(H_{s y n}\right)$ is a clear increase in the inertial power contribution, $\Delta P$ in (1), during the SFR. Two main aspects deserve mention: (i) synthetic inertia controller provides a very fast inertial power contribution with a high $d P / d t$, the effect of this high rate of change on power contribution has a positive effect on the $d f / d t$. The difference on the rate of change of frequency $(\mathrm{ROCOF}=$ $d f / d t)$ is clear on Fig. 7.

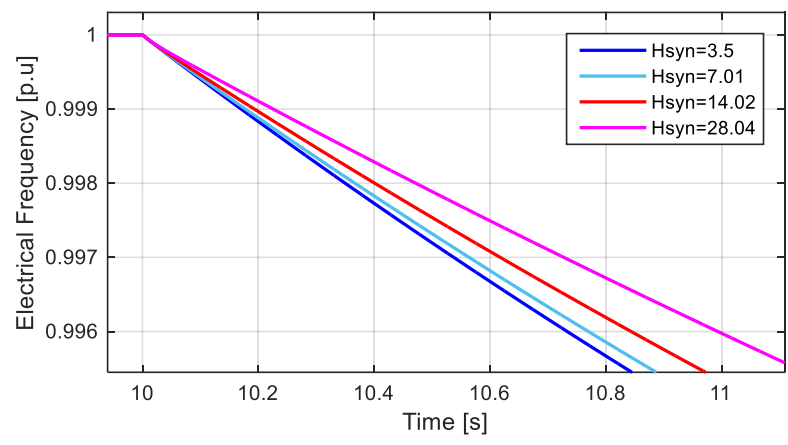

Fig. 7. Details of frequency response considering several values of synthetic inertia controller, $H_{s y n}$.
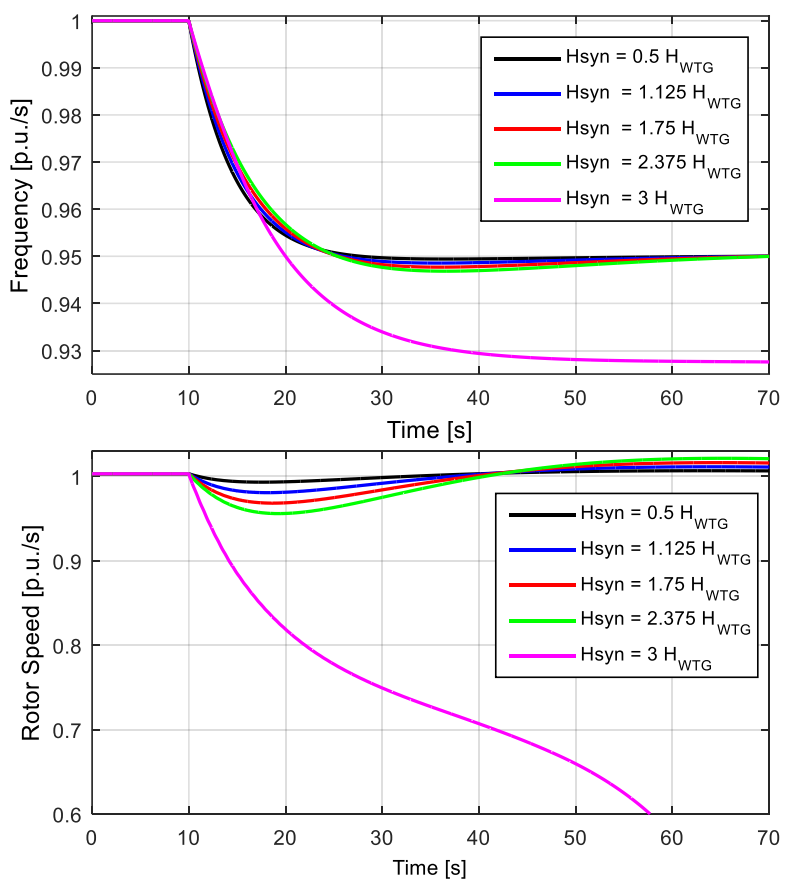

Fig. 8. Simulation results of WT frequency response considering several inertia values, $H_{s y n}$.

Fig 8 shows the simulation results of the frequency response of a WT considering several gain of the synthetic inertia controller $\left(H_{s y n}\right)$. Again, increasing the gain of the inertia controller increases the internal power contribution taking the energy from the rotating parts, as a consequence the generator rotational speed is decreased. Releasing the kinetic energy of the rotating components in the WTG has a limit, as can being seen in Fig. 8 if the gain synthetic inertia controller $\left(H_{s y n}\right)$ is three times the total physical inertia of the WTG $\left(H_{W T G}\right)$, the kinetic energy released using the inertia controller causes a massive rotational speed decreased causing the WTG to stall.

The simulation results presented here, make evident there is a limit on the gain synthetic inertia controller $\left(H_{s y n}\right)$, and this limit is related with the total physical inertia of the WTG $\left(H_{W T G}\right)$, the simulation case presented here demonstrated this value is several times the total physical inertia of the WTG $\left(H_{W T G}\right)$. However, and deeper theoretical; review must be performed in order to define the real limit of the total kinetic energy the can be released from the WTG using the inertia controller without provoking a massive rotational speed decrease and causing the WTG to stall.

\section{CONCLUSIONS}

The preliminary results show, by means of time-domain simulation, a practical limit of the inertia controller gain $\left(H_{s y n t}\right)$ and highlights its relationship with the real wind turbine inertia constant $\left(H_{W T G}\right)$. This limit is extremely important in order to avoid overloading the power converter, but, at the same time, to avoid the wind turbine stall.

\section{REFERENCES}

[1] N. Plc. (2010). National Grid, Grid Code Frequency Response Working Group: "Simulated Inertia". Available: http://www.nationalgrid.com/uk/Electricity/Codes/gridcode/workinggrou $\mathrm{ps} /$ freqresp/

[2] F. Gonzalez-Longatt, A. Bonfiglio, R. Procopio, and B. Verduci, "Evaluation of Inertial Response Controllers for Full-Rated Power Converter Wind Turbine (Type 4)," presented at the 2016 IEEE PES General Meeting, Boston, MA, USA, 2016.

[3] A. Bonfiglio, F. Gonzalez-Longatt, and R. Procopio, "Integrated Inertial and Droop Frequency Controller for Variable Speed Wind Generators," WSEAS Transactions on Environment and Development, vol. 12, pp. 167-177, 2016.

[4] A. A. Bonfiglio, F. Gonzalez-Longatt, and R. Procopio, "Evaluation of Inertial Frequency Support Provided by Variable Speed Wind Generators," presented at the 10th International Conference on Renewable Energy Sources (RES '16), Prague, Czech Republic, 2016.

[5] P. Tielens and D. Van Hertem, "The relevance of inertia in power systems," Renewable and Sustainable Energy Reviews, vol. 55, pp. 9991009, 3// 2016.

[6] NG. (2016). National Grid: Mandatory Frequency Response. Available: http://www2.nationalgrid.com/UK/Services/Balancingservices/Frequency-response/Mandatory-Frequency-Response/

[7] F. Gonzalez-Longatt, "Frequency Control and Inertial Response Schemes for the Future Power Networks," in Advances in Technologies for Generation, Transmission and Storage, Green Energy and Technology Series. vol. VIII, J. Hossain and A. Mahmud, Eds., ed Singapur: Springer-Verlag, 2014, p. 363.

[8] F. Gonzalez-Longatt, "Impact of synthetic inertia from wind power on the protection/control schemes of future power systems: Simulation study," in Developments in Power Systems Protection, 2012. DPSP 2012. 11 th International Conference on, 2012, pp. 1-6.

[9] F. M. Gonzalez-Longatt, "Activation schemes of synthetic inertia controller for full converter wind turbine generators," in PowerTech, 2015 IEEE Eindhoven, 2015, pp. 1-5. 
[10] J. B. Ekamayake, N. Jenkins, and G. Strbac, "Frequency Response From Wind Turbines," Wind Engineering, vol. 32, pp. 537-586, 2008

[11] GE. (2009). WindINERTIA Control fact sheet. Available: http://www.geenergy.com/products and services/products/wind turbines/index.jsp

[12] J. Morren, S. W. H. de Haan, W. L. Kling, and J. A. Ferreira, "Wind turbines emulating inertia and supporting primary frequency control," Power Systems, IEEE Transactions on, vol. 21, pp. 433-434, 2006.

[13] I. Erlich and M. Wilch, "Primary frequency control by wind turbines," in Power and Energy Society General Meeting, 2010 IEEE, 2010, pp. 1-8.

[14] S. Yuan-zhang, Z. Zhao-sui, L. Guo-jie, and L. Jin, "Review on frequency control of power systems with wind power penetration," in Power System Technology (POWERCON), 2010 International Conference on, 2010, pp. 1-8.

[15] J. Ekanayake and N. Jenkins, "Comparison of the response of doubly fed and fixed-speed induction generator wind turbines to changes in network frequency," Energy Conversion, IEEE Transactions on, vol. 19, pp. 800802,2004

[16] R. Doherty, A. Mullane, G. Nolan, D. J. Burke, A. Bryson, and M. O'Malley, "An Assessment of the Impact of Wind Generation on System Frequency Control," Power Systems, IEEE Transactions on, vol. 25, pp. 452-460, 2010.

[17] I. Erlich, W. Winter, and A. Dittrich, "Advanced grid requirements for the integration of wind turbines into the German transmission system," in Power Engineering Society General Meeting, 2006. IEEE, 2006, p. 7 pp.

[18] D. Gautam, L. Goel, R. Ayyanar, V. Vittal, and T. Harbour, "Control Strategy to Mitigate the Impact of Reduced Inertia Due to Doubly Fed
Induction Generators on Large Power Systems," Power Systems, IEEE Transactions on, vol. 26, pp. 214-224, 2011.

[19] N. Miller, K. Clark, and R. Walling, "WindINERTIA: Controlled Inertial Response from GE Wind Turbine Generators," presented at the 45th Annual Minnesota Power Systems Conference, Minneapolis, Minnesota, 2009.

[20] S. Wachtel and A. Beekmann, "Contribution of Wind Energy Converters with Inertia Emulation to Frequency Control and Frequency Stability in Power Systems," presented at the 8th International Workshop on LargeScale Integration of Wind Power into Power Systems as well as on Transmission Networks for Offshore Wind Farms, Bremen, Germany, 2009.

[21] F. Gonzalez-Longatt, "Impact of synthetic inertia from wind power on the protection/control schemes of future power systems: Simulation study," in 11th International Conference on Developments in Power Systems Protection, 2012. DPSP 2012. , 2012, pp. 1-6.

[22] F. M. Gonzalez-Longatt, "Activation schemes of synthetic inertia controller on full converter wind turbine (type 4)," in Power \& Energy Society General Meeting, 2015 IEEE, 2015, pp. 1-5.

[23] F. Gonzalez-Longatt, "Impact of emulated inertia from wind power on under-frequency protection schemes of future power systems," Journal of Modern Power Systems and Clean Energy, pp. 1-8, 2015/08/12 2015.

[24] O. Anaya-Lara, Wind energy generation : modelling and control. Oxford: Wiley, 2009.

[25] T. Ackermann, Wind power in power systems. Chichester: John Wiley \& Sons, 2005 . 